\title{
Management of Delirium in Adult Critically ill Patients: An Overview
}

\author{
Hoan Linh Banh \\ Faculty of Pharmacy and Pharmaceutical Sciences, University of Alberta. \\ Received, May 7, 2012; Revised, July 20, 2012; Accepted, August 9, 2012; Published, August 12, 2012.
}

\begin{abstract}
Delirium is a common manifestation of acute, reversible, brain dysfunction in critically ill patients. It is associated with increased morbidity and mortality in the intensive care unit (ICU). Detection and prevention of risk factors for delirium is critical. Daily assessment for delirium should be part of the treatment strategies. Although, non-pharmacologic treatment have been successful, often, pharmacologic intervention is necessary. Currently, there are no approved medications indicated for the treatment of ICU delirium. The objective of this review article is to provide a comprehensive overview of non-pharmacologic and pharmacologic options for the treatment of ICU delirium.
\end{abstract}

This article is open to POST-PUBLICATION REVIEW. Registered readers (see "For Readers") may comment by clicking on ABSTRACT on the issue's contents page.

\section{BACKGROUND}

Delirium is defined as a disturbance of consciousness characterized by an acute onset of impaired cognitive function (1). Its development is associated with the underlying medical conditions, substance abuse, adverse effects of medications, substance withdrawal, or a combination of these risk factors (2). Agitation, a manifestation of delirium, is defined as frequent movements of the head, arms, or legs, and/or ventilator - patient dysynchrony despite efforts to calm the patient (3). Patients may also experience delirium as a form of mental disturbance that is less obvious and referred to as quiet agitation (4). Delirium are classified as either hypoactive (not agitated), hyperactive (agitated), or mixed (5).

The pathophysiology of delirium in intensive care unit (ICU) is poorly understood. It is hypothesized that there is an imbalance in the synthesis, release and inactivation of neurotransmitters (6). Cholinergic deficiency and excessive dopamine are thought to contribute to delirium.(7-10). Dopamine increases and acetylcholine decreases result in neuronal excitability (11). Other neurotransmitters such as GABA and serotonin have been implicated in delirium $(9,12)$.

Although delirium is considered to be common in ICU, there are few studies that have evaluated its incidence, risks, and outcomes $(3,4)$. Risk factors are categorized into two groups: predisposing risk factors and precipitating factors $(4,13,14)$. (Table 1). ICU delirium is associated with increased morbidity, and mortality and increased cost to the healthcare system $(15,16)$.

In addition to the uncertainty of the incidence of ICU delirium, there is a lack of information about the effects that certain pharmacological treatments have on delirious patients. For example, do certain medications exacerbate/alleviate delirium, increase/decrease its incidence, prolong/reduce delirious states, increase/decrease ICU length of stay, and/or increase/decrease morbidity and mortality?

\section{ASSESSMENT}

There are numerous assessment tools available to identify, diagnose and classify the severity of ICU delirium. The two most widely validated assessment tools used are the confusion assessment methodICU (CAMICU), and intensive care delirium screening checklist (ICDSC) $(17,18)$. The ICDSC is a screening checklist of eight items based on diagnostic and statistical manual of mental disorders (DSM) criteria and features of delirium including inattention, disorientation, hallucination-

Corresponding Author: Dr. H.L. Banh. Faculty of Pharmacy and Pharmaceutical Sciences, University of Alberta, 3-227 Edmonton Clinic Health Academy, Edmonton, AB, Email hoan@ualberta.ca 


\begin{tabular}{ll}
\hline Table 1. Risk factors for ICU delirium & \\
\hline PREDISPOSING FACTORS & PRECIPITATING FACTORS \\
\hline Age greater than 65 & Prolonged pain \\
Respiratory disease & Psychoactive drugs such as benzodiazepines \\
Cognitive impairment & Sleep deprivation \\
Depression & Severity of illness \\
Alcoholism & Severe sepsis \\
Smoking & hypoxemia \\
\hline
\end{tabular}

delusion psychosis, psychomotor agitation or retardation, inappropriate speech or mood, sleep/wake cycle disturbances, and symptom fluctuation according to a total score system of 0 to 8 points. A patient with a score of more than 4 points is defined as delirium positive. It is designed to be easy to use by the clinicians at the bedside and requires minimal time for the assessment. There is evidence to suggest that the ICDSC enhances the ability to accurately detect ICU delirium (18).

\section{NON-PHARMACOLOGIC PREVENTION}

Non-pharmacologic interventions are targeted to prevent or reverse potential contributors to the development of delirium. Recent studies have shown that delirium may be an independent risk factor for increased mortality in an ICU setting (19). Because delirium is a multi-factorial syndrome, it usually treated with a multi-component protocol which focuses on six delirium factors: 1) cognitive impairment, 2) sleep deprivation, 3) dehydration, 4) vision/hearing impairment, 5) early mobilization 6) psychoactive medications (20). It has been shown that multi-factorial interventions are effective and decreases the duration of delirium (21-23). The limitation for these studies is, they were conducted in non-ICU patients. However, the risk factors addressed in the studies are commonly seen in ICU patients.

\section{Daily awakening trials}

Often ICU patients receive analgesics and sedatives for pain control, comfort, and minimize anxiety while receiving mechanical ventilation (5). Numerous medications used in the ICU can have deleterious effects and could increase the risk for delirium. Evidence suggests there is an independent dose related association between lorazepam and progression to delirium $(1,4,16)$. At present, there is little evidence to show whether other benzodiazepines have the same effect on the incidence and duration of delirium. Evidence of delirium associated with morphine is unclear (1). However, patients received morphine for hip fracture have been shown as a risk factor for Delirium (24). Daily awaking trials involve discontinuing sedation and analgesia to allow patients to awaken and responsive. Once patients reached certain targeted responsiveness and awareness, the sedation and analgesia are to be restarted at $50 \%$ of the dose and titrate to effect. This process will ensure the lowest dose of sedation and analgesics used and avoid drug accumulation in patients who may require long ICU stay. The daily interruption of sedation and analgesia provides an opportunity for the medical staff to assess patients' neurologic status, and pain level (25-27). Studies showed that daily interruption of sedation result in improved psychological functions, shorter duration of mechanism ventilation requirement, decreased length of stay in ICU and reduced need for diagnostic tests without an increase in complications (27-29).

\section{Environmental factors}

There are no data on primary prevention of ICU delirium by controlling environmental factors. However, there are studies that focused in non-ICU settings aimed on minimized these risk factors. It has been recognized that the environmental factors such as hospital, contribute to delirium, and making changes to the environment surrounding the patients can prevent delirium $(30,31)$. Non-pharmacologic strategies include repeated re-orientation of patients to day/night cycle, maintain regular activities for cognitive stimulation, providing and using eyeglasses, hearing aids, and reduce or minimize noise level $(32,33)$. Because ICU delirium prevention data is not currently available, it may be helpful to extrapolate the evidence from non-ICU delirium until ICU delirium studies are conducted. 


\section{Noise Reduction}

Several enhancements and improvements can be implemented to promote a healing environment for patients in ICU. In a survey to evaluate experiences of critically ill patients in the ICU, $54 \%$ of respondents were concerned with the noise level in the ward (34). It has been shown that ICU with all the alarms and multiple monitoring devices is one of the noisiest units in the hospital (35). National agencies such as the World Health Organization, has set standards for maximum noise levels in the hospital (36). The noise recommendation from the World Health Organization for hospital settings are $35 \mathrm{~dB}(\mathrm{~A})$ during the day and $30 \mathrm{~dB}(\mathrm{~A})$ at night. In many institutions attempts are being made to reduce the level of noise by discontinuing the use of unnecessary monitors or equipment, minimize telephone use and conversation around patient bedside, adjust alarm volume to the lowest safe level, and use of ear plugs for patients having difficulties with noise $(5,37)$.

\section{PHARMACOLOGIC TREATMENT}

Currently, no drugs have received approval from Health Canada and US Food Drug Administration for the treatment of ICU delirium. Nevertheless, antipsychotic agents are routinely used based on outcome evidence. These medications may be helpful in treating the symptoms of delirium by exerting a stable balance by antagonizing the neurotransmitters such as dopamine and serotonin $(38,38,39)$.

\section{Typical antipsychotic \\ Haloperidol}

Haloperidol is a butyrophenone antipsychotic. It is a $\mathrm{D}_{2}$ receptor antagonist. The exact mechanism of action in ICU delirium is unclear. It is theorized that blockade of $\mathrm{D}_{2}$ receptor results in amelioration of hallucination, delusions and unconstructed thought patterns $(40,41)$. It is recommended as the drug of choice to treat ICU delirium by the Society of Critical Care Medicine and American Psychiatry Association.(42-44). Intravenous haloperidol, although off-label, is currently used to treat ICU delirium (5). The effective dose for ICU delirium has not been established. Depending on the severity of the delirium the common dose used is $2-10 \mathrm{mg}$ intravenously every six hours(43). Serious side effects include extrapyramidal symptoms such as acute dystonic reactions, subactue parkinsonism, and akathisia, dose-dependent QTc prolongation, and neuroleptic malignant syndrome (44). Continuous infusions of haloperidol have been used to treat severe ICU delirium $(45,46)$. Close cardiac monitoring is recommended as QTc prolongations were reported by the authors. The use of continuous infusions should be limited to patients who required rapid titration of haloperidol to control acute symptoms, and large intermittent doses (47). Recent evidence indicated that haloperidol in high doses may cause a paradoxical effect by prolonging the duration of delirium $(5,48$ $50)$.

\section{Chlorpromazine}

Chlorpromazine is a phenothiazine antipsychotic. It is a potent $\mathrm{D}_{1}$, and $\mathrm{D}_{2}$ antagonist. Inhibition of these receptors accounts for ameliorates different antipsychotic symptoms. Currently no study has been conducted in ICU patients with chlorpromazine. It is equally effective compared to haloperidol in terminal AIDS patients with delirium but chlorpromazine has a less favourable side effect profile (51). Undesirable side effects caused by chlorpromazine include anticholinergic activities, hypotension, tachycardia, cardiac arrhythmias, and EPS which limits its use. In addition, chlorpromazine has been shown to lower seizure threshold (52). Due to the serious side effects, chlorpromazine is generally not recommended for ICU delirium.

\section{Atypical antipsychotic}

Atypical antipsychotics such as olanzapine, risperidone, quetiapine, and ziprasidone, began to gain popularity in the treatment of ICU delirium in early 2000. It is believed to be as effective but have fewer side effects such as extrapyramidal symptoms than haloperidol. Because atypical antipsychotics have a relatively high affinity for $5-\mathrm{HT}_{2 \mathrm{~A}}$ receptor than $\mathrm{D}_{2}$ receptor, it is thought to be associated with less extrapyramidal symptoms (53-55) (Tables $2-$ 3 ). Currently, there is limited evidence to support the use of atypical antipsychotics in ICU delirium. 


\begin{tabular}{ll}
\hline Table 2. Adverse effects of receptor blockade) \\
\hline RECEPTOR & ADVERSE EFFECTS \\
\hline $\mathbf{D}_{2}$ & Extrapyramidal symptoms \\
$\propto_{1}$ & Hypotension \\
$\mathbf{H}_{1}$ & Sedation and weight gain \\
$\mathbf{5 - H \mathbf { T } _ { 2 }}$ & Increased appetite and weight gain \\
$\mathbf{M}_{1}$ & Cognitive deficits, dry mouth, constipation, increased heart rate, urinary retention, blurred \\
& vision \\
\hline D, dopamine; $\propto$, & alpha, H, histamine; 5-HT, serotonin; M, muscarinic; adopted from 11, 56, 57. \\
\hline
\end{tabular}

\begin{tabular}{|c|c|c|c|c|}
\hline \multicolumn{4}{|c|}{ RELATIVE RECEPTOR AFFINITY } & Ziprasidone \\
\hline Dopamine (2) & ++++ & +++ & ++++ & ++++ \\
\hline Serotonin & +++ & + & +++ & ++++ \\
\hline$\propto_{1}$ & ++ & +++ & +++ & ++ \\
\hline Histamine & +++ & +++ & + & + \\
\hline Muscarinic & + & - & - & - \\
\hline \multicolumn{5}{|c|}{ ADVERSE EFFECTS } \\
\hline Sedation & +++ & +++ & ++ & ++ \\
\hline $\begin{array}{l}\text { Extrapyramidal } \\
\text { symptoms }\end{array}$ & $+++*$ & + & $+++*$ & + \\
\hline Anticholinergic & +++ & ++ & + & + \\
\hline Hypotension & +++ & ++++ & ++++ & ++ \\
\hline Hyperglycemia & +++ & ++ & + & + \\
\hline QTe prolongation & $?$ & $?$ & + & $+++*$ \\
\hline
\end{tabular}

\section{Olanzapine}

A prospective randomized controlled trial compared olanzapine with haloperidol in the treatment of ICU delirium (67). The study showed the once daily 5 $\mathrm{mg}$ olanzapine doses were as effective as haloperidol $2.5 \mathrm{mg}-5 \mathrm{mg}$ enterally three times a day. The duration of the study was for five days. There was no difference in the reduction of delirium index between two groups. A significantly more rescued intravenous haloperidol doses were required in the haloperidol group. However, the dose and route of administration of haloperidol used in the study is not standard of practice for ICU delirium. The standard of practice is to administer haloperidol intravenously for ICU delirium. In the study, it was given enterally. Because the bioavailability of oral/enteral formulation is different than intravenous formulation, haloperidol given IV maybe more superior to oral olanzapine. Also, the doses in the study were not consistent with the standard haloperidol doses used in the ICU. Extrapyramidal symptoms were reported in six patients in haloperidol group, and none in olanzapine group. However, the investigators did not assess for QTc prolongation. The authors concluded that olanzapine is a safe alternative to haloperidol.

\section{Quetiapine}

A double-blind, placebo controlled, multicenter study evaluated the efficacy and safety of quetiapine (68). Although this is the first study to compare the drug with placebo, rescue intravenous haloperidol were allowed to be used in both groups. The results showed quetiapine associated with quicker resolution of delirium, reduced time of delirium and agitation, and reduced haloperidol requirement compared to placebo. There was no difference in the duration of ICU stay, length of hospitalization, and hospital mortality. More adverse events such as somnolence, and hypotension were reported in quetiapine group than 
placebo but not statistically significant. There was no difference in the incidence of QTc prolongation in both groups. In the study, patients must tolerate enteral nutrition, and without a complicating neurologic condition such as hypoactive delirium. Gastroparesis is a wellknown complication developed in ICU patients and often some patients could not tolerate enteral feeding despite the administration of a GI motility agent. Also, by excluding hypoactive delirium, there is a strong potential for premature assumptions about resolution of symptoms. Due to the strict exclusion criteria, patients in the study do not truly represent commonly seen patients in the ICU. In general, quetiapine was well tolerated. The authors suggest further randomized, controlled trials are needed to evaluate the role quetiapine in ICU delirium.

\section{Risperidone}

Currently, there is only one published study on risperidone in the treatment of delirium. The subjects in this study are mixed ICU and non-ICU patients (69). There were no statistical differences in the mean delirium rating score, time to effect, and frequency of response between the groups. Because of the small sample size (24 patients), and the lack of consensus as to optimal dosage of haloperidol or risperidone, the authors could not offer conclusive evidence as to superiority of one drug over another. There was no report of clinically significant side effects. One patient in the haloperidol group show mild symptoms of akathisia but did not require medical treatment. Nevertheless, there have been reports of increased risk of delirium and stroke with risperidone, particularly in elderly patients $(70,71)$. Risperidone should be used with caution especially in elderly. Regulatory agencies such as FDA and Health Canada issued a black box warning regarding elderly patients with dementia treated with risperidone are at an increased risk of cerebrovascular adverse events such as stroke and transient ischemic attacks, and death compared to placebo. The authors suggest larger randomized, controlled studies are necessary to confirm the results.

\section{Ziprasidone}

Ziprasidone is a newer atypical antipsychotic agent. It is potent $\mathrm{D}_{2}$ and $5-\mathrm{HT}_{2 \mathrm{~A}}$ receptorantagonist (72). A multicentre, randomized, double-blind, placebo- controlled trial was conducted in ICU delirium with ziprasidone, haloperidol and placebo (73). All three groups were given additional intravenous haloperidol on as needed basis. The duration of the study was 14 days regardless of the patient clinical status. A total of 101 patients distributed evenly in all three groups were included in the study. The results showed treatment with antipsychotics did not improve the number of days alive without delirium or coma nor it increased adverse events when compared with placebo. However, more patients in the placebo group required additional haloperidol compared to the treatment groups. Reported incidences of akathisia were similar and not clinically significant in both antipsychotic groups. Fewer patients in the ziprasidone group experienced extrapyramidal symptoms than the haloperidol and placebo groups. However, this difference did not reach statistically significance. There was no difference in the incidents of QTc prolongation among three groups. The authors concluded that the use of antipsychotics in ICU patients is feasible but larger studies are needed to determine the appropriateness of these agents in this setting.

\section{ALPHA-RECEPTOR ANTAGONISTS}

\section{Dexmedetomidine}

Dexmedetomidine, a potent selective $\alpha_{2}$ agonist indicated for sedation during procedures and in ICU for long term ( $>24$ hour). It produces sedation and analgesia without causing respiratory depression (74). Common side effects are hypotension, and bradycardia. Clinical trial showed dexmedetomidine had a lower incidence and duration of delirium compared to midazolam (45). A double blinded, randomized controlled trial using dexmedetomidine compared with lorazepam for sedation to determine the effects of on the duration of delirium and coma mechanically ventilated ICU patients (75). The treatment group experienced significantly more median days alive without delirium or comma (75). Dexmedetomadine was associated with less incidence of delirium and shorter duration of mechanical ventilation requirement. Patients in the treatment group had a higher incidence of sinusbradycardia, and there was no difference in self-extubations between two groups. There was a trend, although insignificant toward increased in atrial fibrillation in dexmedetomidine group. Economic assessments of 
the use of dexmedetomidine in sedation demonstrated a better clinical consequences and economic impact when compared with midazolam $(75,76)$. However, there are conflicting data indicating dexmedetomidine increases the incidence of delirium (77). Although studies showed promising results, more data are required to determine the efficacy and safety of dexmedetomidine in the prevention and treatment of ICU delirium.

\section{Clonidine}

Clonidine is an $\alpha_{2}$ agonist indicated for hypertension. It is also has analgesic, sedative and anxiolytic properties (78). It has been used as an adjunct in the treatment of narcotic, ethanol, and tobacco withdrawal (79-81). In a study with intravenous clonidine, the investigators concluded clonidine reduces the severity of delirium, improves the respiratory function, decrease the weaning duration and the ICU length of stay after surgery (82). A limitation in using clonidine in Canada is, currently, intravenous clonidine is only available through Health Canada Special Assess Programme.

\section{OTHER AGENT}

\section{Rivastigmine}

Evidence suggests that impaired cholinergic neurotransmission plays an important role in the development of delirium $(8,10,12)$. It has been shown that there is a strong correlation between increased anticholinergic activity and the development of delirium in particular with elderly patients

(83).

Acetylcholinesterase inhibitors inhibit the cholinesterase enzyme preventing the destruction of acetylcholine. This results in increased level duration of acetylcholine. Rivastigmine is an acetylcholinesterase and butyrylcholinesterase inhibitor indicated for Alzheimer's disease, Parkinson's disease dementia, and Lewy-body dementia. Cholinesterase inhibitors such as rivastigmine have been successfully used to treat delirium in elderly patients (84-87). A recent study investigates the use of rivastigmine as an adjunct to haloperidol in ICU patients with delirium (88). Unfortunately, the study was terminated prematurely due to increased mortality in the rivastigmine group. The investigators concluded that rivastigmine did not reduce the duration of delirium, hence, the use of rivastigmine in the treatment of ICU delirium was not recommended.

\section{COMPLEMENTARY AND ALTERNATIVE MEDICINE}

Complementary and alternative medicine (CAM) is a broad category of therapies, treatments, and use of products that are not considered mainstream conventional (Western) medicine $(89,90)$. CAM is classified into five categories:(89)

1. Medical systems which includes ayurvedic medicine, Chinese medicine, and homeopathy/naturopathic medicine.

2. Mind-body medicine includes animal-assisted therapy, art therapy, guided imagery, meditation, music therapy, and prayer.

3. Biologically based practices include dietary supplements, and herbal products.

4. Manipulative/body based practices involves acupressure, chiropractic/manipulative therapy and massage.

5. Energy medicine consists of Qi gong, reiki, therapeutic touch and bioelectromagnetic-based therapies.

It has been suggested that CAM may provide additional modalities for managing patients with delirium in ICU. Most critical care nurses view the use of CAM positively and are receptive to their use (91-95). The common CAMs used in ICU are diet, counseling/psychology, relaxation techniques, massage, prayer, and music therapy.

\section{Music Therapy}

Music intervention consists of the use of preferred music to achieve a therapeutic goal (92). Studies in mechanically ventilated ICU patients listening to preferred music, and relaxing music, through a headphone showed a reduction in anxiety, and physiological stress response from stress (96-99).

\section{Promotion of Sleep}

Most ICU patients develop impaired sleep pattern due to the use of opioids and benzodiazepines as well as other environmental factors which affect the rapid eye movement sleep $(13,14,100)$. One of the consequences from impaired sleep is delirium (101). There are strong association between sleep deprivation and delirium in elderly, postoperative patients, and ICU patients $(13,14,101)$. 


\section{Quiet time protocol}

In an effort to promote sleep in the ICU, a quiet time protocol was developed to reduce noise and light levels at specific time twice a day. The study showed a significant increased of observed sleep after the protocol was implemented $(37,102)$.

\section{Relaxation}

Progressive muscle relaxation can decrease muscle tension, reduce stress, and help in pain control (92). This will help patients achieve the state of relaxation which will promote better sleep.

\section{Massage}

Massage is commonly utilized by nurses in the ICU to prepare patients for sleep $(103,104)$. Massage does not require special equipment and basic techniques can be easily learned and remembered by caregivers.

\section{Melatonin}

Melatonin, a hormone, plays an important role in the regulation of the sleep-wake cycle (105). Disruption of the sleep-wake cycle, with fragmented sleep during the night and sleepiness during the day, is frequently observed during delirium (106). Studies indicate an association between delirium and interrupted melatonin secretion (107-111). Despite evidence suggest that exogenous melatonin supplementation would regulate sleep cycle, results from studies did not demonstrate better sleep (112-114). The limitations of these studies include a lack of consistent sleep assessment, and control of environmental factors. Due to lack of randomized controlled studies to show safety and efficacy in the treatment or prevention of ICU delirium, melatonin is not recommended.

It is evident that critical care nurses are using CAM in the ICU. However, they acknowledge that there are many barriers in their ability to implement the practice. The barriers included a lack of knowledge and training in CAM, a lack of allowed time and physician reluctance to use CAM (95). Also, CAM is not innocuous. For example, relaxation is typically considered a positive response for patients who are under stress. However, relaxation tends to reduce blood pressure, heart rate and respiratory rate (115), which a critically ill patient may not be able to tolerate. In addition, patients may be hypersensitive to touch and may experience negative response such as anxiety. Before incorporating CAM into the plan of care for ICU patients, a careful evaluation of ICU confounders such as openness to use of CAM by providers, and resources available is needed.

\section{CONCLUSION}

Delirium is a serious complication in critically ill patients associated with increased morbidity and mortality. Patients should be assessed for delirium daily. Currently, there is a lack of randomized control trials with pharmacological treatments in ICU delirium. The complexity of medical condition exists in ICU patients limits the feasibility in recruiting homogenous study subjects for large randomized, controlled trials. Non-pharmacologic approach in the treatment of non-ICU delirium has been implemented in the ICU with success. However, caution is warranted when extrapolating results from pharmacologic treatments in non-ICU patients to ICU patients. In the case of rivastigmine, it was shown to be effective non-ICU delirium but increased mortality in ICU patients without benefit. The recommended drug of choice by both the Intensive Care Society and the American College of Critical Care Medicine is haloperidol. The strategies in managing ICU delirium should include prevention, identify risk factors, diagnosis and treatment with nonpharmacologic and pharmacologic modalities.

\section{REFERENCES}

1. Bergeron N, Skrobik Y, Dubois MJ. Delirium in critically ill patients. Crit Care. 2002 Jun;6(3):181-2.

2. Lacasse H, Perreault MM, Williamson DR. Systematic review of antipsychotics for the treatment of hospital-associated delirium in medically or surgically ill patients. Ann Pharmacother. 2006 Nov;40(11):1966-73.

3. Jaber S, Chanques G, Altairac C, Sebbane M, Vergne C, Perrigault PF, et al. A prospective study of agitation in a medical-surgical ICU: Incidence, risk factors, and outcomes. Chest. 2005 Oct;128(4):2749-57.

4. Ouimet S, Kavanagh BP, Gottfried SB, Skrobik Y. Incidence, risk factors and consequences of ICU delirium. Intensive Care Med. 2007 Jan;33(1):66-73.

5. Jacobi J, Fraser GL, Coursin DB, Riker RR, Fontaine D, Wittbrodt ET, et al. Clinical practice guidelines for the sustained use of sedatives and analgesics in the critically ill adult. Crit Care Med. 2002 Jan;30(1):119-41. 
6. Trzepacz PT. Update on the neuropathogenesis of delirium. Dement Geriatr Cogn Disord. 1999 SepOct;10(5):330-4.

7. Gaudreau JD, Gagnon P. Psychotogenic drugs and delirium pathogenesis: The central role of the thalamus. Med Hypotheses. 2005;64(3):471-5.

8. Flacker JM, Cummings V, Mach JR,Jr, Bettin K, Kiely DK, Wei J. The association of serum anticholinergic activity with delirium in elderly medical patients. Am J Geriatr Psychiatry. 1998 Winter;6(1):31-41.

9. Trzepacz PT. Delirium. advances in diagnosis, pathophysiology, and treatment. Psychiatr Clin North Am. 1996 Sep;19(3):429-48.

10. van Gool WA, van de Beek D, Eikelenboom P. Systemic infection and delirium: When cytokines and acetylcholine collide. Lancet. 2010 Feb 27;375(9716):773-5.

11. Reynolds GP. Receptor mechanisms in the treatment of schizophrenia. J Psychopharmacol. 2004 Sep;18(3):340-5.

12. Trzepacz PT. The neuropathogenesis of delirium. A need to focus our research. Psychosomatics. 1994 Jul-Aug;35(4):374-91.

13. Dubois MJ, Bergeron N, Dumont M, Dial S, Skrobik Y. Delirium in an intensive care unit: A study of risk factors. Intensive Care Med. 2001 Aug;27(8):1297304.

14. Aldemir M, Ozen S, Kara IH, Sir A, Bac B. Predisposing factors for delirium in the surgical intensive care unit. Crit Care. 2001 Oct;5(5):265-70.

15. Milbrandt EB, Deppen S, Harrison PL, Shintani AK, Speroff T, Stiles RA, et al. Costs associated with delirium in mechanically ventilated patients. Crit Care Med. 2004 Apr;32(4):955-62.

16. Pandharipande P, Shintani A, Peterson J, Pun BT, Wilkinson GR, Dittus RS, et al. Lorazepam is an independent risk factor for transitioning to delirium in intensive care unit patients. Anesthesiology. 2006 Jan;104(1):21-6.

17. Plaschke K, von Haken R, Scholz M, Engelhardt R, Brobeil A, Martin E, et al. Comparison of the confusion assessment method for the intensive care unit (CAM-ICU) with the intensive care delirium screening checklist (ICDSC) for delirium in critical care patients gives high agreement rate(s). Intensive Care Med. 2008 Mar;34(3):431-6.

18. Devlin JW, Fong JJ, Schumaker G, O'Connor H, Ruthazer R, Garpestad E. Use of a validated delirium assessment tool improves the ability of physicians to identify delirium in medical intensive care unit patients. Crit Care Med. 2007 Dec;35(12):2721,4; quiz 2725.

19. Ely EW, Shintani A, Truman B, Speroff T, Gordon $\mathrm{SM}$, Harrell FE,Jr, et al. Delirium as a predictor of mortality in mechanically ventilated patients in the intensive care unit. JAMA. 2004 Apr 14;291(14):1753-62.

20. Inouye SK, Baker DI, Fugal P, Bradley EH, for the HELP Dissemination Project. Dissemination of the hospital elder life program: Implementation, adaptation, and successes. J Am Geriatr Soc. 2006 Oct;54(10):1492-9.

21. Lundstrom M, Edlund A, Karlsson S, Brannstrom B, Bucht G, Gustafson Y. A multifactorial intervention program reduces the duration of delirium, length of hospitalization, and mortality in delirious patients. $\mathbf{J}$ Am Geriatr Soc. 2005 Apr;53(4):622-8.

22. Marcantonio ER, Flacker JM, Wright RJ, Resnick NM. Reducing delirium after hip fracture: A randomized trial. J Am Geriatr Soc. 2001 May;49(5):516-22.

23. Milisen K, Foreman MD, Abraham IL, De Geest S, Godderis J, Vandermeulen E, et al. A nurse-led interdisciplinary intervention program for delirium in elderly hip-fracture patients. J Am Geriatr Soc. 2001 May;49(5):523-32.

24. Morrison RS, Magaziner J, Gilbert M, Koval KJ, McLaughlin MA, Orosz G, et al. Relationship between pain and opioid analgesics on the development of delirium following hip fracture. $\mathbf{J}$ Gerontol A Biol Sci Med Sci. 2003 Jan;58(1):76-81.

25. Kress JP, Pohlman AS, Hall JB. Sedation and analgesia in the intensive care unit. Am J Respir Crit Care Med. 2002 Oct 15;166(8):1024-8.

26. Carson SS, Kress JP, Rodgers JE, Vinayak A, Campbell-Bright S, Levitt J, et al. A randomized trial of intermittent lorazepam versus propofol with daily interruption in mechanically ventilated patients. Crit Care Med. 2006 May;34(5):1326-32.

27. Kress JP, Gehlbach B, Lacy M, Pliskin N, Pohlman AS, Hall JB. The long-term psychological effects of daily sedative interruption on critically ill patients. Am J Respir Crit Care Med. 2003 Dec 15;168(12):1457-61.

28. Berry E, Zecca H. Daily interruptions of sedation: A clinical approach to improve outcomes in critically ill patients. Crit Care Nurse. 2012 Feb;32(1):43-51.

29. Dotson B. Daily interruption of sedation in patients treated with mechanical ventilation. Am J Health Syst Pharm. 2010 Jun 15;67(12):1002-6.

30. Inouye SK, Bogardus ST,Jr, Charpentier PA, LeoSummers L, Acampora D, Holford TR, et al. A multicomponent intervention to prevent delirium in hospitalized older patients. N Engl J Med. 1999 Mar 4;340(9):669-76.

31. Inouye SK. Predisposing and precipitating factors for delirium in hospitalized older patients. Dement Geriatr Cogn Disord. 1999 Sep-Oct;10(5):393-400.

32. Inouye SK, Bogardus ST,Jr, Williams CS, LeoSummers L, Agostini JV. The role of adherence on the effectiveness of nonpharmacologic interventions: 
Evidence from the delirium prevention trial. Arch Intern Med. 2003 Apr 28;163(8):958-64.

33. Siddiqi N, Stockdale R, Britton AM, Holmes J. Interventions for preventing delirium in hospitalised patients. Cochrane Database Syst Rev. 2007 Apr 18;(2)(2):CD005563.

34. Hofhuis JG, Spronk PE, van Stel HF, Schrijvers AJ, Rommes JH, Bakker J. Experiences of critically ill patients in the ICU. Intensive Crit Care Nurs. 2008 Oct;24(5):300-13.

35. Busch-Vishniac IJ, West JE, Barnhill C, Hunter T, Orellana D, Chivukula R. Noise levels in johns hopkins hospital. J Acoust Soc Am. 2005 Dec;118(6):3629-45.

36. Guidelines for community noise. [Internet]. Available from: http://whqlibdoc.who.int/hq/1999/a68672.pdf.

37. Scotto CJ, McClusky C, Spillan S, Kimmel J. Earplugs improve patients' subjective experience of sleep in critical care. Nurs Crit Care. 2009 JulAug;14(4):180-4.

38. Hipp DM, Ely EW. Pharmacological and nonpharmacological management of delirium in critically ill patients. Neurotherapeutics. 2012 Jan;9(1):158-75.

39. Girard TD, Pandharipande PP, Ely EW. Delirium in the intensive care unit. Crit Care. 2008;12 Suppl 3:S3.

40. Kapur S, Remington G, Jones C, Wilson A, DaSilva $\mathrm{J}$, Houle S, et al. High levels of dopamine D2 receptor occupancy with low-dose haloperidol treatment: A PET study. Am J Psychiatry. 1996 Jul;153(7):948-50.

41. Wolkin A, Brodie JD, Barouche F, Rotrosen J, Wolf AP, Smith M, et al. Dopamine receptor occupancy and plasma haloperidol levels. Arch Gen Psychiatry. 1989 May;46(5):482-4.

42. Jones SF, Pisani MA. ICU delirium: An update. Curr Opin Crit Care. 2012 Apr;18(2):146-51.

43. Practice guideline for the treatment of patients with delirium. american psychiatric association. Am J Psychiatry. 1999 May;156(5 Suppl):1-20.

44. The management of the agitated ICU patient. Crit Care Med. 2002 Jan;30(1 Suppl Management):S97,123; quiz S124-25.

45. Riker RR, Fraser GL, Cox PM. Continuous infusion of haloperidol controls agitation in critically ill patients. Crit Care Med. 1994 Mar;22(3):433-40.

46. Seneff MG, Mathews RA. Use of haloperidol infusions to control delirium in critically ill adults. Ann Pharmacother. 1995 Jul-Aug;29(7-8):690-3.

47. Trujillo $\mathrm{MH}$, Bellorin-Font E. Drugs commonly administered by intravenous infusion in intensive care units: A practical guide. Crit Care Med. 1990 Feb;18(2):232-8.

48. Rea RS, Battistone S, Fong JJ, Devlin JW. Atypical antipsychotics versus haloperidol for treatment of delirium in acutely ill patients. Pharmacotherapy. 2007 Apr;27(4):588-94.

49. Skrobik Y. Haloperidol should be used sparingly. Crit Care Med. 2002 Nov;30(11):2613,4; author reply 2614.

50. Pisani MA, Murphy TE, Araujo KL, Slattum P, Van Ness PH, Inouye SK. Benzodiazepine and opioid use and the duration of intensive care unit delirium in an older population. Crit Care Med. 2009 Jan;37(1):177-83.

51. Breitbart W, Marotta R, Platt MM, Weisman H, Derevenco M, Grau C, et al. A double-blind trial of haloperidol, chlorpromazine, and lorazepam in the treatment of delirium in hospitalized AIDS patients. Am J Psychiatry. 1996 Feb;153(2):231-7.

52. Mayo-Smith MF, Beecher LH, Fischer TL, Gorelick DA, Guillaume JL, Hill A, et al. Management of alcohol withdrawal delirium. an evidence-based practice guideline. Arch Intern Med. 2004 Jul 12;164(13):1405-12.

53. Altar CA, Wasley AM, Neale RF, Stone GA. Typical and atypical antipsychotic occupancy of D2 and $\mathrm{S} 2$ receptors: An autoradiographic analysis in rat brain. Brain Res Bull. 1986 Apr;16(4):517-25.

54. Meltzer HY, Matsubara S, Lee JC. Classification of typical and atypical antipsychotic drugs on the basis of dopamine D-1, D-2 and serotonin $2 \mathrm{pKi}$ values. $\mathrm{J}$ Pharmacol Exp Ther. 1989 Oct;251(1):238-46.

55. Rasmussen K, Aghajanian GK. Potency of antipsychotics in reversing the effects of a hallucinogenic drug on locus coeruleus neurons correlates with 5-HT2 binding affinity. Neuropsychopharmacology. 1988 May;1(2):101-7.

56. Baldessarini RJ TF. Drugs and the treatment of psychiatric disorders. In: Hardman JG LL, editor. Goodman \& Gilman's The Pharmacological Basics of Therapeutics. ; 2001. p. 485-520.

57. Trichard C, Paillere-Martinot ML, Attar-Levy D, Recassens C, Monnet F, Martinot JL. Binding of antipsychotic drugs to cortical 5-HT2A receptors: A PET study of chlorpromazine, clozapine, and amisulpride in schizophrenic patients. Am J Psychiatry. 1998 Apr;155(4):505-8.

58. Gilchrist NA, Asoh I, Greenberg B. Analytic reviews: Atypical antipsychotics for the treatment of ICU delirium. J Intensive Care Med. 2011 Mar 25.

59. Miller DD. Atypical antipsychotics: Sleep, sedation, and efficacy. Prim Care Companion J Clin Psychiatry. 2004;6(Suppl 2):3-7.

60. Tarsy D, Baldessarini RJ, Tarazi FI. Effects of newer antipsychotics on extrapyramidal function. CNS Drugs. 2002;16(1):23-45.

61. Haddad PM, Sharma SG. Adverse effects of atypical antipsychotics : Differential risk and clinical implications. CNS Drugs. 2007;21(11):911-36.

62. Patel JK, Buckley PF, Woolson S, Hamer RM, McEvoy JP, Perkins DO, et al. Metabolic profiles of 
second-generation antipsychotics in early psychosis: Findings from the CAFE study. Schizophr Res. 2009 Jun;111(1-3):9-16.

63. Stahl S. Describing an antipsychotic: Receptor binding and its role in pathophysiology. Primary care companion to the Journal of clinical psychiatry. 2003;5(suppl 3):9-13.

64. Karan R, Pandhi P. D2 and 5HT2 receptors: Relevance to antipsychotic drugs. Indian Journal of Pharmacology. 2000;32:187-91.

65. Markowitz JS, Brown CS, Moore TR. Atypical antipsychotics. part I: Pharmacology, pharmacokinetics, and efficacy. Ann Pharmacother. 1999 Jan;33(1):73-85.

66. Brown CS, Markowitz JS, Moore TR, Parker NG. Atypical antipsychotics: Part II: Adverse effects, drug interactions, and costs. Ann Pharmacother. 1999 Feb;33(2):210-7.

67. Skrobik YK, Bergeron N, Dumont M, Gottfried SB. Olanzapine vs haloperidol: Treating delirium in a critical care setting. Intensive Care Med. 2004 Mar;30(3):444-9.

68. Devlin JW, Roberts RJ, Fong JJ, Skrobik Y, Riker RR, Hill NS, et al. Efficacy and safety of quetiapine in critically ill patients with delirium: A prospective, multicenter, randomized, double-blind, placebocontrolled pilot study. Crit Care Med. 2010 Feb;38(2):419-27.

69. Han CS, Kim YK. A double-blind trial of risperidone and haloperidol for the treatment of delirium. Psychosomatics. 2004 Jul-Aug;45(4):297301.

70. Tavcar R, Dernovsek MZ. Risperidone-induced delirium. Can J Psychiatry. 1998 Mar;43(2):194.

71. Ravona-Springer R, Dolberg OT, Hirschmann S, Grunhaus L. Delirium in elderly patients treated with risperidone: A report of three cases. J Clin Psychopharmacol. 1998 Apr;18(2):171-2.

72. Goodnick PJ. Ziprasidone: Profile on safety. Expert Opin Pharmacother. 2001 Oct;2(10):1655-62.

73. Girard TD, Pandharipande PP, Carson SS, Schmidt GA, Wright PE, Canonico AE, et al. Feasibility, efficacy, and safety of antipsychotics for intensive care unit delirium: The MIND randomized, placebocontrolled trial. Crit Care Med. 2010 Feb;38(2):42837.

74. Gerlach AT, Murphy CV, Dasta JF. An updated focused review of dexmedetomidine in adults. Ann Pharmacother. 2009 Dec;43(12):2064-74.

75. Pandharipande PP, Pun BT, Herr DL, Maze M, Girard TD, Miller RR, et al. Effect of sedation with dexmedetomidine vs lorazepam on acute brain dysfunction in mechanically ventilated patients: The MENDS randomized controlled trial. JAMA. 2007 Dec 12;298(22):2644-53.

76. Lachaine J, Beauchemin C. Economic evaluation of dexmedetomidine relative to midazolam for sedation in the intensive care unit. Can J Hosp Pharm. 2012 Mar;65(2):103-10.

77. Ruokonen E, Parviainen I, Jakob SM, Nunes S, Kaukonen M, Shepherd ST, et al. Dexmedetomidine versus propofol/midazolam for long-term sedation during mechanical ventilation. Intensive Care Med. 2009 Feb;35(2):282-90.

78. O'brien C. Drug addictions and drug abuse. In: Hardman JG LL, editor. Goodman \& Gilman's The Pharmacological Basis of Therapeutics. ; 2001. p. 621-42.

79. Bond WS. Psychiatric indications for clonidine: The neuropharmacologic and clinical basis. J Clin Psychopharmacol. 1986 Apr;6(2):81-7.

80. Glassman AH, Stetner F, Walsh BT, Raizman PS, Fleiss JL, Cooper TB, et al. Heavy smokers, smoking cessation, and clonidine. results of a double-blind, randomized trial. JAMA. 1988 May 20;259(19):2863-6.

81. Gold MS, Redmond DE,Jr, Kleber HD. Clonidine blocks acute opiate-withdrawal symptoms. Lancet. 1978 Sep 16;2(8090):599-602.

82. Rubino AS, Onorati F, Caroleo S, Galato E, Nucera $\mathrm{S}$, Amantea $\mathrm{B}$, et al. Impact of clonidine administration on delirium and related respiratory weaning after surgical correction of acute type-A aortic dissection: Results of a pilot study. Interact Cardiovasc Thorac Surg. 2010 Jan;10(1):58-62.

83. Golinger RC, Peet T, Tune LE. Association of elevated plasma anticholinergic activity with delirium in surgical patients. Am J Psychiatry. 1987 Sep;144(9):1218-20.

84. Overshott R, Karim S, Burns A. Cholinesterase inhibitors for delirium. Cochrane Database Syst Rev. 2008 Jan 23;(1)(1):CD005317.

85. Overshott R, Vernon M, Morris J, Burns A. Rivastigmine in the treatment of delirium in older people: A pilot study. Int Psychogeriatr. 2010 Aug;22(5):812-8.

86. Oldenbeuving AW, de Kort PL, Jansen BP, Kappelle LJ, Roks G. A pilot study of rivastigmine in the treatment of delirium after stroke: A safe alternative. BMC Neurol. 2008 Sep 20;8:34.

87. Fischer P. Successful treatment of nonanticholinergic delirium with a cholinesterase inhibitor. J Clin Psychopharmacol. 2001 Feb;21(1):118.

88. van Eijk MM, Roes KC, Honing ML, Kuiper MA, Karakus A, van der Jagt $M$, et al. Effect of rivastigmine as an adjunct to usual care with haloperidol on duration of delirium and mortality in critically ill patients: A multicentre, double-blind, placebo-controlled randomised trial. Lancet. 2010 Nov 27;376(9755):1829-37.

89. National institutes of health. what is complementary and alternative medicine? [online] july 2011 [cited 2011 oct 10]. available from: 
Http://nccam.nih.gov/health/whatiscam/\#definingca $\mathrm{m}$ [Internet].

90. Natural health products directorate. baseline natural health products survey among consumers: Final report. natural health products directorate; 2005.

91. Cooke M, Mitchell M, Tiralongo E, Murfield J. Complementary and alternative medicine and critical care nurses: A survey of knowledge and practices in australia. Aust Crit Care. 2012 Jan 25.

92. Tracy MF, Lindquist R, Savik K, Watanuki S, Sendelbach S, Kreitzer MJ, et al. Use of complementary and alternative therapies: A national survey of critical care nurses. Am J Crit Care. 2005 Sep;14(5):404,14; quiz 415-16.

93. Lindquist R, Tracy MF, Savik K. Personal use of complementary and alternative therapies by critical care nurses. Crit Care Nurs Clin North Am. 2003 Sep;15(3):393,9, x.

94. Lindquist R, Tracy MF, Savik K, Watanuki S. Regional use of complementary and alternative therapies by critical care nurses. Crit Care Nurse. 2005 Apr;25(2):63,4, 66-8, 70-2 passim.

95. Tracy MF, Lindquist R, Watanuki S, Sendelbach S, Kreitzer MJ, Berman B, et al. Nurse attitudes towards the use of complementary and alternative therapies in critical care. Heart Lung. 2003 MayJun;32(3):197-209.

96. Dijkstra BM, Gamel C, van der Bijl JJ, Bots ML, Kesecioglu J. The effects of music on physiological responses and sedation scores in sedated, mechanically ventilated patients. J Clin Nurs. 2010 Apr;19(7-8):1030-9.

97. Chlan L. Effectiveness of a music therapy intervention on relaxation and anxiety for patients receiving ventilatory assistance. Heart Lung. 1998 May-Jun;27(3):169-76.

98. Chlan LL. Psychophysiologic responses of mechanically ventilated patients to music: A pilot study. Am J Crit Care. 1995 May;4(3):233-8.

99. Wong HL, Lopez-Nahas V, Molassiotis A. Effects of music therapy on anxiety in ventilator-dependent patients. Heart Lung. 2001 Sep-Oct;30(5):376-87.

100.Krachman SL, D'Alonzo GE, Criner GJ. Sleep in the intensive care unit. Chest. 1995 Jun;107(6):1713-20.

101. Yildizeli B, Ozyurtkan MO, Batirel HF, Kuscu K, Bekiroglu N, Yuksel M. Factors associated with postoperative delirium after thoracic surgery. Ann Thorac Surg. 2005 Mar;79(3):1004-9.

102. Olson DM, Borel CO, Laskowitz DT, Moore DT, McConnell ES. Quiet time: A nursing intervention to promote sleep in neurocritical care units. Am J Crit Care. 2001 Mar;10(2):74-8.
103.Richards KC. Effect of a back massage and relaxation intervention on sleep in critically ill patients. Am J Crit Care. 1998 Jul;7(4):288-99.

104.Richards KC, Gibson R, Overton-McCoy AL. Effects of massage in acute and critical care. AACN Clin Issues. $2000 \mathrm{Feb}$;11(1):77-96.

105.Brzezinski A. Melatonin in humans. N Engl J Med. 1997 Jan 16;336(3):186-95.

106. Gupta N, de Jonghe J, Schieveld J, Leonard M, Meagher D. Delirium phenomenology: What can we learn from the symptoms of delirium? J Psychosom Res. 2008 Sep;65(3):215-22.

107.Lewis MC, Barnett SR. Postoperative delirium: The tryptophan dyregulation model. Med Hypotheses. 2004;63(3):402-6.

108. Magri F, Sarra S, Cinchetti W, Guazzoni V, Fioravanti M, Cravello L, et al. Qualitative and quantitative changes of melatonin levels in physiological and pathological aging and in centenarians. J Pineal Res. 2004 May;36(4):256-61.

109. Haimov I, Laudon M, Zisapel N, Souroujon M, Nof D, Shlitner A, et al. Sleep disorders and melatonin rhythms in elderly people. BMJ. 1994 Jul 16;309(6948):167.

110.Balan S, Leibovitz A, Zila SO, Ruth M, Chana W, Yassica B, et al. The relation between the clinical subtypes of delirium and the urinary level of 6-SMT. J Neuropsychiatry Clin Neurosci. 2003 Summer;15(3):363-6.

111. Shigeta H, Yasui A, Nimura $\mathrm{Y}$, Machida N, Kageyama M, Miura M, et al. Postoperative delirium and melatonin levels in elderly patients. Am J Surg. 2001 Nov;182(5):449-54.

112.Ibrahim MG, Bellomo R, Hart GK, Norman TR, Goldsmith D, Bates S, et al. A double-blind placebocontrolled randomised pilot study of nocturnal melatonin in tracheostomised patients. Crit Care Resusc. 2006 Sep;8(3):187-91.

113. Bourne RS, Mills GH, Minelli C. Melatonin therapy to improve nocturnal sleep in critically ill patients: Encouraging results from a small randomised controlled trial. Crit Care. 2008;12(2):R52.

114. Shilo L, Dagan Y, Smorjik Y, Weinberg U, Dolev S, Komptel B, et al. Effect of melatonin on sleep quality of COPD intensive care patients: A pilot study. Chronobiol Int. 2000 Jan;17(1):71-6.

115.van den Boogaard M, Schoonhoven L, Evers AW, van der Hoeven JG, van Achterberg T, Pickkers P. Delirium in critically ill patients: Impact on longterm health-related quality of life and cognitive functioning. Crit Care Med. 2012 Jan;40(1):112-8. 